\title{
Evolutionary Insights into IL17A in Lagomorphs
}

\author{
Fabiana Neves, ${ }^{1,2}$ Joana Abrantes, ${ }^{1}$ Tereza Almeida, ${ }^{1}$ \\ Paulo P. Costa, ${ }^{2,3}$ and Pedro J. Esteves ${ }^{1,4,5}$ \\ ${ }^{1}$ CIBIO, InBIO-Research Network in Biodiversity and Evolutionary Biology, Universidade do Porto, Campus de Vairão, \\ Rua Padre Armando Quintas, 4485-661 Vairão, Portugal \\ ${ }^{2}$ Unidade Multidisciplinar de Investigação Biomédica (UMIB), Universidade do Porto (UP), Rua de Jorge Viterbo Ferreira, \\ No. 228, 4050-313 Porto, Portugal \\ ${ }^{3}$ Departamento de Genética, CSPGF, Instituto Nacional de Saúde Dr. Ricardo Jorge, Rua Alexandre Herculano, No. 321, \\ 4000-055 Porto, Portugal \\ ${ }^{4}$ Departamento de Biologia, Faculdade de Ciências da Universidade do Porto, Rua do Campo Alegre, s/n, 4169-007 Porto, Portugal \\ ${ }^{5}$ Centro de Investigação em Tecnologias de Saúde (CITS), CESPU, Rua Central de Gandra, No. 1317, 4585-116 Gandra, Portugal
}

Correspondence should be addressed to Pedro J. Esteves; pjesteves@cibio.up.pt

Received 22 September 2015; Accepted 22 November 2015

Academic Editor: Kong Chen

Copyright (c) 2015 Fabiana Neves et al. This is an open access article distributed under the Creative Commons Attribution License, which permits unrestricted use, distribution, and reproduction in any medium, provided the original work is properly cited.

In leporids, IL17A had been implicated in the host defense against extracellular pathogens, such as Francisella tularensis that infects hares and rabbits and causes the zoonotic disease tularemia. Here, we studied IL17A from five lagomorphs, European rabbit, pygmy rabbit, brush rabbit, European brown hare, and American pika. We observed that this protein is highly conserved between these species, with a similarity of $97-99 \%$ in leporids and $\sim 88 \%$ between leporids and American pika. The exon/intron structure, Nglycosylation sites, and cysteine residues are conserved between lagomorphs. However, at codon 88 , one of the interaction sites between IL17A and its receptor IL17RA, there is an Arg $>$ Pro mutation that only occurs in European rabbit and European brown hare. This could induce critical alterations in the IL17A structure and conformation and consequently modify its function. The differences observed between leporids and humans or rodents might also represent important alterations in protein structure and function. In addition, as for other interleukins, IL17A sequences of human and European rabbit are more closely related than the sequences of human and mouse or European rabbit and mouse. This study gives further support to the hypothesis that European rabbit might be a more suitable animal model for studies on human IL17.

\section{Introduction}

Interleukin 17, first known as cytotoxic T lymphocyte associated antigen (CTLA) 8, is originated from a T-cell derived factor with cytokine-like activity $[1,2]$. With a ubiquitous expression in different tissues, this protein, nowadays known as IL17A, has a sequence composition different from all the other cytokine families $[1,3]$. IL17A, along with five functional homodimers (IL17B-F), one heterodimer (IL17A/F), and 5 receptors (IL17RA-RE), composes the IL17 family, which is important to adaptive immunity responses, namely, as mediator of chronic inflammation and autoimmune diseases [3-6]. There is a wide range of genes that are targeted by IL17, such as proinflammatory and hematopoietic cytokines, genes associated with acute phase response, and antimicrobial substances $[3,7]$. This protein is also part of a subset of CD4 T helper (Th) cells known as Thl7 which are able to establish a connection between innate and adaptive immune responses, being a complement to Th1 and Th2 defense mechanisms [8]. Furthermore, the production of IL17A is important for host defense against extracellular pathogens (fungi, viruses, bacteria, and parasites) assisting in neutrophils recruitment and activation and also promoting antimicrobial peptides [8-12]. Studies in mice [12-15] and humans [16-18] highlighted the importance of IL17 expressing cells for immunity against several diseases, and low expression levels of IL17 and IL17RA make organisms more susceptible to disease, including those caused by extracellular pathogens such as Francisella tularensis. 
F. tularensis is highly pathogenic Gram negative intracellular bacteria included by the Center of Disease Control and Prevention (CDC) in category A of bioterrorism (http://emergency.cdc.gov/agent/agentlist.asp). Able to cause the zoonotic disease tularemia, this microorganism has several known hosts, from mammals to protozoans; however transmission to humans is normally associated with direct contact with lagomorphs, rodents, and some arthropods $[15$, 20-22]. In lagomorphs and rodents, F. tularensis has the ability to cause septicemia while in humans the outcome of infection is a multisystem organ failure [23]. There are several reports of $F$. tularensis infections in leporids, mainly in rabbits (European rabbit and cottontails) [24-26] and hares $[24,26,27]$ and despite an apparent period of stasis (20062010) there were some recently documented outbreaks of tularemia in Europe [22, 28].

The order Lagomorpha includes two families, Leporidae (rabbits and hares) with eleven genera and Ochotonidae (pikas) with only one genus, Ochotona [29]. Together with rodents, lagomorphs form the clade Glires, a sister group of Euarchonta that includes primates [30, 31]. Along with mouse, the European rabbit had been used as a research model for several human diseases, development of therapeutics and vaccines [32]. Several studies have suggested that the European rabbit may be a better research model than mouse [33-37]. With the exception of humans and mouse, there is a big gap of information on IL17A in other mammalian groups, including leporids. Thus, considering the important biological role of the European rabbit immune response against several diseases, including tularemia, we performed a genetic characterization of IL17A in four leporid genera (Oryctolagus, Brachylagus, Sylvilagus, and Lepus).

\section{Material and Methods}

Samples of European rabbit (Oryctolagus cuniculus cuniculus and Oryctolagus cuniculus algirus), pygmy rabbit (Brachylagus idahoensis), brush rabbit (Sylvilagus bachmani), and European brown hare (Lepus europaeus) were provided by the CIBIO Lagomorpha tissue collection. Genomic DNA (gDNA) was extracted using the EasySpin Genomic DNA Minipreps Tissue Kit (Citomed, Torun, Poland) according to the manufacturer's instructions. Total RNA was extracted by using the RNeasy Mini Kit also according to the manufacturer's instructions (Qiagen, Hilden, Germany) from one specimen of European rabbit and one of European brown hares. Complementary DNA (cDNA) was synthesized using oligo(dT) as primers and SuperScript III reverse transcriptase (Invitrogen, Carlsbad, CA, USA). The European rabbit and American pika IL17A sequences were retrieved from public databases (accession numbers are given in bold in Figure 1). PCR amplification was performed with the Multiplex PCR Kit (Qiagen) by using two pairs of primers designed according to the retrieved sequences (for genomic DNA F1CGTCCAACCTCAGTTGATC + R1-CACTGTACCATCTATCCTGC and F2-CCTTCATTTACTCCCATTCG + R2CATCCATCACATGGCCTAA; for cDNA the combination of primers $\mathrm{F} 1+\mathrm{R} 2$ was used). Sequencing was performed on an ABI PRISM 310 Genetic Analyzer (PE Applied Biosystems,
Foster City, CA, USA) and PCR products were sequenced in both directions. The sequences obtained were submitted to GenBank with the following accession numbers: KU163611KU163619.

Haplotype phases of the sequences obtained were reconstructed with the program PHASE, built into the software DnaSP [38]. Multiple Sequence Comparison by LogExpectation (MUSCLE; http://www.ebi.ac.uk/) [39] was used for sequence alignment. The putative $\mathrm{N}$-glycosylation sites were predicted using NetNGlyc 1.0 (http://www.cbs.dtu.dk/ services/NetNGlyc/) [40].

The number of nucleotide differences per site between sequences was estimated in MEGA6 [41] with the following options: bootstrap method (1000 replicates), p-distance as model, and pairwise deletion for gaps/missing data treatment. A Maximum Likelihood approach was used to estimate the phylogenetic relationships between the IL17A nucleotide sequences by using MEGA6; the best-fit nucleotide substitution model was predicted by the same software and 1000 bootstrap replicates were used.

The secondary structure of IL17A was predicted using PsiPred (http://bioinf.cs.ucl.ac.uk/psipred/) [42, 43] and DiAminoacid Neural Network Application (DiANNA) (http:// clavius.bc.edu/ clotelab/DiANNA/) [44]. Both methods predict protein cysteines that create disulfide bonds, but while PsiPred uses Position Specific Iterated-BLAST (PSI-BLAST) to obtain evolutionary information used to predict the secondary structure of the query protein, DiANNA is a neural network that recognizes cysteines in an oxidized state (sulfur covalently bonded) distinguishing them from those in a reduced state.

\section{Results and Discussion}

In this study we amplified and sequenced the IL17A gene for four leporids species (European rabbit, European brown hare, brush rabbit, and pygmy rabbit). For European rabbit (O.c. cuniculus) and European brown hare, both genomic and cDNA sequences were identical and only one of the sequences is presented; however both sequences have been assigned different accession numbers. These sequences were further compared to sequences of IL17A from another lagomorph, American pika (Ochotona princeps), and from representatives of the most relevant mammalian groups (e.g., Artiodactyla, carnivores, Chiroptera, Primates, rodents, etc.) available in online databases. In the European rabbit, IL17A is located in the forward strand of chromosome 12 and has a similar structure to other mammals with three coding exons. The IL17A cDNA sequence obtained in this work for Lepus europaeus showed a similar structure.

In humans, IL17A codes for a protein with 155 amino acids (aa) and has the ability to bind with high affinity to IL17RA and IL17RC $[6,45,46]$. The interaction between interleukins and their receptors is crucial for their function and signaling and any changes in the amino acid composition may induce alterations in the protein conformation. In humans and rodents these interactions sites are described $[6,45]$ and include Leu52, Ile54, Ser61, Ser70-Tyr72, Arg75, Arg84, Arg88-Val94, Trp96, Leu103, His114, His115, Asn117, 
European rabbit XM_002714498.2 European rabbit (O. c. cuniculus) ${ }^{*} 1$ European rabbit (O.c. cuniculus) ${ }^{*} 2$ European rabbit (O. c. algirus)

European brown hare

Brush rabbit

Pygmy rabbit

American pika XM_004590436.2

Human NM_002190.2

Mouse NM 010552.3

Rat NM 001106897.1

Pig NM 001005729.1

Cattle NM_001008412

Cattle NM_001008412.2

Horse NM_001143792.1

Large flying fox XM_011379067.1

Killer whale XM_004285605.1

Chinese tree shrew XM_006170444.1

Lesser hedgehog tenrec XM_013004266.1

Common shrew XM_012932129.1

African bush elephant XM_003404140.1

Sunda flying lemur XM_008589729.1

European hedgehog XM 007516519.1

Nine-banded armadillo XM_004463779.1

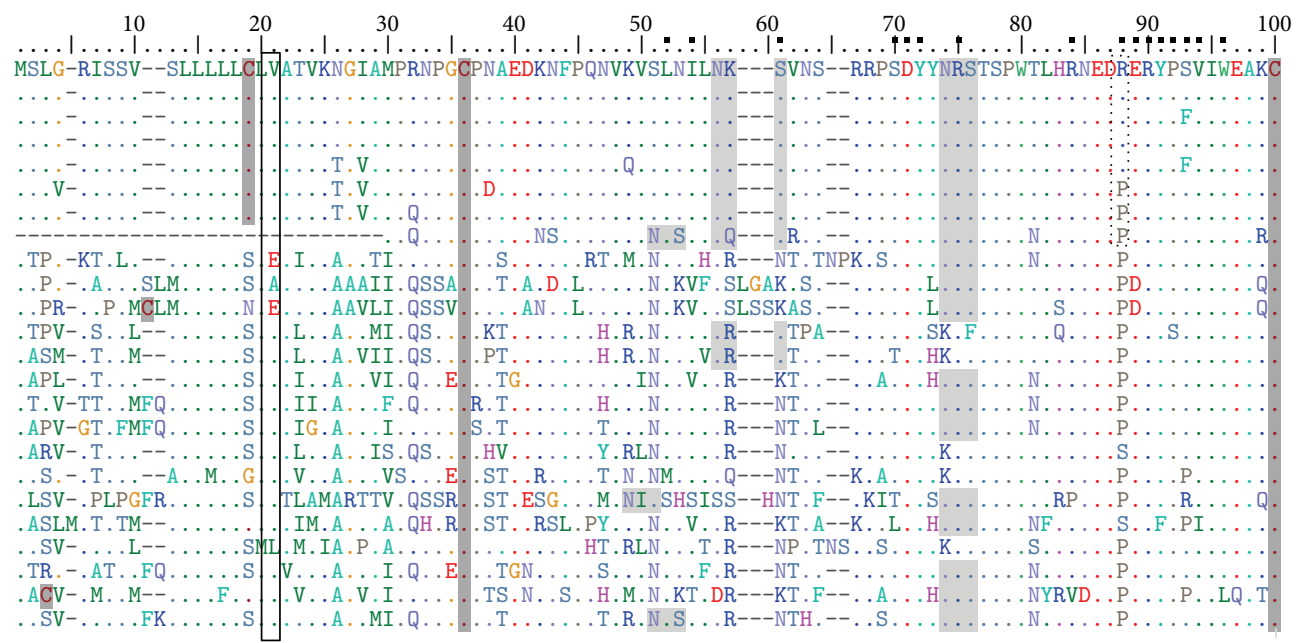

European rabbit XM_002714498.2

European rabbit (O.c.cuniculus) *1

European rabbit (O.c.cuniculus) $* 2$

European rabbit (O. c. algirus)

European brown hare

Brush rabbit

Pygmy rabbit

American pika XM 004590436.2

Human NM_002190.2

Mouse NM_010552.3

Rat NM_001106897.1

Pig NM_001005729.1

Cattle NM_001008412.2

Horse NM_001143792.1

Dog NM 001165878.1

Large flying fox XM 011379067.1

Killer whale XM 004285605.1

Chinese tree shrew XM_006170444.1

Lesser hedgehog tenrec XM_013004266.1

Common shrew XM_012932129.1

African bush elephant XM_003404140.1

Sunda flying lemur XM_008589729.1

European hedgehog XM__007516519.1

Nine-banded armadillo XM 004463779.1

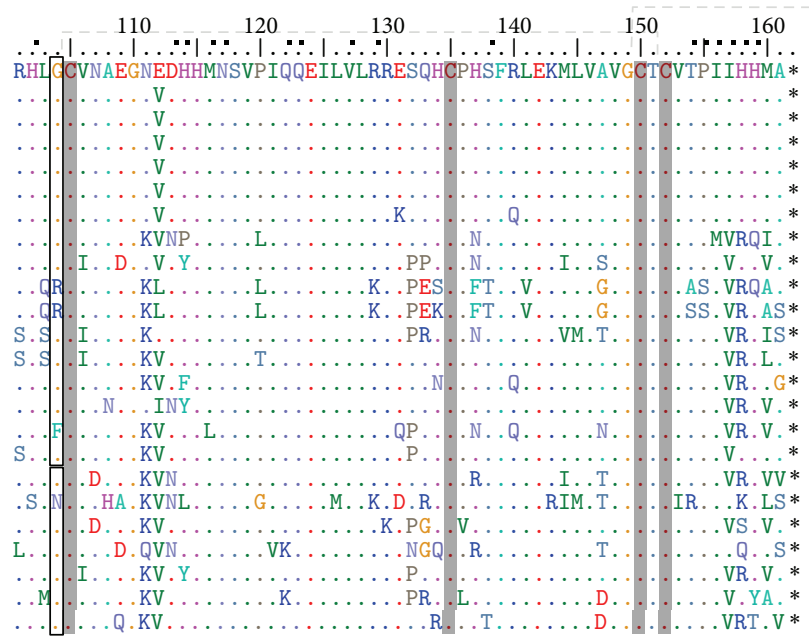

FIGURE 1: Alignment of IL17A for several mammalian species. GenBank and Ensembl accession numbers are indicated in bold for the retrieved sequences. Positively selected amino acids are boxed (according to [19]). N-glycosylation sites are shaded in light grey and cysteine residues are shaded in dark grey. A black dashed box represents the Agr>Pro mutation between leporids. * represents stop codons; - represents indels; - above the numbering represents the sites important for IL17A-IL17Ra interaction. ${ }^{*} 1$ and ${ }^{*} 2$ represent different alleles. Numbering is according to the European rabbit sequence (GenBank accession number XM_002714498.2) and the signal peptide and indels were included in the numbering. Disulfide bonds between side chain cysteines are represented by a light grey dashed line.

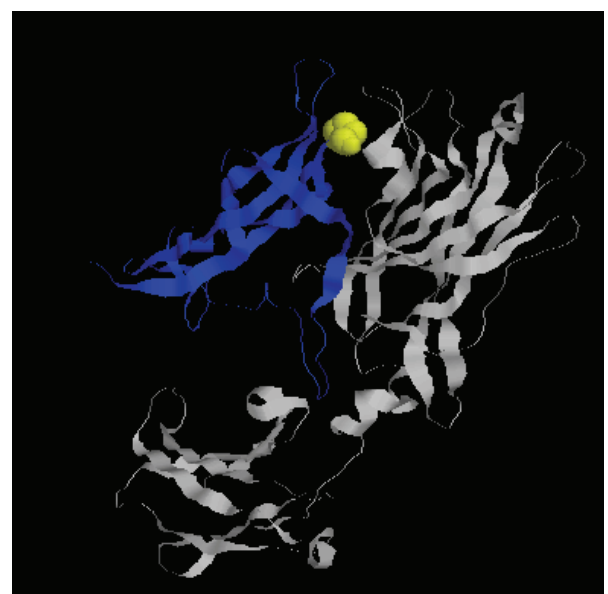

FIgURE 2: 3D structures of the IL17A-IL17RA complex. IL17A appears in blue while IL17RA appears in grey. Marked in yellow is the $88 \mathrm{Arg}>$ Pro mutation described for leporids.
Ser118, Gln122-Glu124, Leu128, Arg130, Phe139, and Pro155Met160 (Figure 1). In leporids, IL17A codes for a protein with 153 aa and we observed that the sites that likely interact with the receptors are quite conserved. Indeed, from the thirtythree amino acids involved in the linkage between IL17A and IL17RA, eighteen are conserved: twelve are maintained between mammals and the other six, despite being different, do not alter the charge or the polarity. For the remaining fifteen amino acids, only three are differently charged, seven have distinct polarity, and five have both different charge and polarity (Table 1). Between leporids these sites are highly conserved, but a mutation was observed that is located in the external coil of the IL17A in a site where this protein interacts with IL17RA (Figure 2). This mutation, 88Arg > Pro, occurs in the European rabbit and in the European brown hare, while in brush rabbit and the American pika the amino acid present is a proline as in most mammals. Some studies showed that Arg $>$ Pro mutations have crucial effects in the 
TABLE 1: Characterization of the IL17A amino acids differences in the sites important for binding to IL17RA.

\begin{tabular}{|c|c|c|c|c|c|}
\hline \multirow{3}{*}{ Amino acid position } & \multicolumn{5}{|c|}{ Amino acids } \\
\hline & \multicolumn{4}{|c|}{ Leporids } & \multirow{2}{*}{ Other mammals } \\
\hline & European rabbit & European brown hare & Brush rabbit & Pygmy rabbit & \\
\hline 52 & & $\underline{L}^{\#}$ & & & $\mathrm{M}^{\#}, \mathrm{~S}^{*}$ \\
\hline 54 & & $\underline{I}^{\#}$ & & & $\mathrm{~V}^{\#}, \mathrm{~S}^{*}, \mathrm{~T}^{*}$ \\
\hline 61 & & $\mathrm{~S}^{*}$ & & & $\underline{\mathrm{N}}^{*}, \mathrm{~K}^{*+}$ \\
\hline 70 & & $\underline{S}^{*}$ & & & $\mathrm{~T}^{*}, \mathrm{~L}^{\#}$ \\
\hline 71 & & & $\mathrm{D}^{*-}$ & & \\
\hline 72 & & & $\mathrm{Y}^{*}$ & & \\
\hline 75 & & & $\mathrm{R}^{*+}$ & & \\
\hline 84 & & $\underline{\mathrm{R}}^{*+}$ & & & $\mathrm{P}^{\#}, \mathrm{~V}^{\#}$ \\
\hline 88 & & $\mathrm{R}^{*+}$ & & $\mathrm{P}^{\#}$ & $\underline{\mathrm{P}}^{\#}, \mathrm{~S}^{*}$ \\
\hline 89 & & $\underline{\mathrm{E}}^{*-}$ & & & $\mathrm{D}^{*-}$ \\
\hline 90 & & & $\mathrm{R}^{*+}$ & & \\
\hline 91 & & $\underline{\mathrm{Y}}^{*}$ & & & $\mathrm{~F}^{\#}$ \\
\hline 92 & & $\underline{\mathrm{P}}^{\#}$ & & & $S^{*}$ \\
\hline 93 & $\underline{\mathrm{S}}^{*}, \mathrm{~F}^{\#}$ & $\mathrm{~F}^{\#}$ & & $S^{*}$ & $\mathrm{~F}^{\#}, \mathrm{P}^{\#}, \mathrm{R}^{*+}$ \\
\hline 94 & & & $\mathrm{~V}^{\#}$ & & \\
\hline 96 & & $\underline{\mathrm{W}}^{\#}$ & & & $\mathrm{~L}^{\#}$ \\
\hline 103 & & $\overline{L^{\#}}$ & & & $\mathrm{Q}^{*}, \mathrm{~S}^{*}, \mathrm{M}^{\#}$ \\
\hline 114 & & $\overline{\mathrm{H}}^{*+}$ & & & $\mathrm{P}^{\#}, \underline{\mathrm{Y}}^{*}, \mathrm{~F}^{\#}, \mathrm{~L}^{\#}$ \\
\hline 115 & & & $\mathrm{H}^{*+}$ & & \\
\hline 117 & & & $\mathrm{~N}^{*}$ & & \\
\hline 118 & & & $\mathrm{~S}^{*}$ & & \\
\hline 122 & & $\mathrm{Q}^{*}$ & & & $\mathrm{~K}^{*+}$ \\
\hline 123 & & & $\mathrm{Q}^{*}$ & & \\
\hline 124 & & & $\mathrm{E}^{*-}$ & & \\
\hline 128 & & & $\mathrm{~L}^{\#}$ & & \\
\hline 130 & & $\underline{\mathrm{R}}^{*+}$ & & & $\mathrm{K}^{*+}$ \\
\hline 139 & & & $\mathrm{~F}^{\#}$ & & \\
\hline 155 & & $\underline{\mathrm{P}}^{\#}$ & & & $\mathrm{~S}^{*}$ \\
\hline 156 & & $\underline{I}^{\#}$ & & & $\mathrm{M}^{\#}$ \\
\hline 157 & & $\mathrm{I}^{\#}$ & & & $\underline{\mathrm{V}}^{\#}$ \\
\hline 158 & & $\underline{\mathrm{H}}^{*+}$ & & & $\mathrm{S}^{*}, \mathrm{R}^{*+}, \mathrm{Q}^{*}, \mathrm{~K}^{*+}$ \\
\hline 159 & & $\underline{\mathrm{H}}^{*+}$ & & & $\mathrm{Q}^{*}, \mathrm{Y}^{*}, \mathrm{~T}^{*}$ \\
\hline 160 & & $\overline{\mathrm{M}}^{\#}$ & & & $\mathrm{I}^{\#}, \underline{\mathrm{V}}^{\#}, \mathrm{~A}, \mathrm{~L}^{\#}$ \\
\hline
\end{tabular}
sequence is underlined. Numbering is according to the European rabbit IL17A sequence.

protein function [47-49]. Indeed, the 332Arg $>$ Pro mutation in human Trim $5 \alpha$ restricts infection by HIV-1 (Human Immunodeficiency Virus-1) [49] while the 132Arg > Pro mutation in the helicase protein of coronavirus infectious bronchitis virus was lethal to infectivity in vitro [48]. Additionally, this mutation alters the physiochemical properties of the amino acid by changing from a basic polar and positively charged arginine to a nonpolar and neutral proline.

Disulfide bounds and N-glycosylation sites (Asn-XSer/Thr/Cys motifs where $\mathrm{X}$ can be any amino acid except proline) are important for the protein structure, stability, and function [50-52]. Disulphide bounds occur between cysteines side chains and these linkages are also important for protein protection [53]. In human and rodents, IL17A has a cysteine knot fold characterized by two sets of paired $\beta$ strands (1/2 and 3/4) interconnected by two disulfide bounds between strands 2 and 4 linked between four conserved cysteines (Cys100-Cys150 and Cys105-Cys152) [45, 54, 55]. In addition to these cysteines two other cysteines are common to all mammals, Cys36 and Cys135. For the European rabbit, the PsiPred predicted secondary structure and the DiANNA predicted disulfide bonds results are in agreement with those obtained and described for human and rodents $[45,54]$. An extra linkage is also predicted between Cys31 and Cys135. When compared to other mammals, there is an extra cysteine (Cys19) in leporids located in the signal peptide. The rat and 
TABLE 2: IL17A nucleotide distances (the lowest values are in bold and the highest values are underlined).

\begin{tabular}{|c|c|c|c|c|c|c|c|c|c|}
\hline & 1 & 2 & 3 & 4 & 5 & 6 & 7 & 8 & 9 \\
\hline (1) European_rabbit (O.c.cuniculus) & - & & & & & & & & \\
\hline (2) European_rabbit (O.c. algirus) & 0.002 & - & & & & & & & \\
\hline (3) European brown hare & 0.011 & 0.013 & - & & & & & & \\
\hline (4) Brush rabbit & 0.011 & 0.013 & 0.013 & - & & & & & \\
\hline (5) Pygmy rabbit & 0.024 & $\underline{0.026}$ & $\underline{0.026}$ & 0.022 & - & & & & \\
\hline (6) American pika XM_004590436.2 & 0.112 & 0.115 & 0.120 & 0.112 & 0.112 & - & & & \\
\hline (7) Human NM_002190.2 & 0.169 & 0.171 & 0.175 & 0.171 & 0.173 & 0.159 & - & & \\
\hline (8) Mouse NM_010552.3 & $\underline{0.251}$ & 0.251 & 0.249 & 0.249 & 0.245 & 0.240 & $\underline{0.236}$ & - & \\
\hline (9) Rat NM_001106897.1 & 0.260 & 0.260 & 0.258 & 0.258 & 0.253 & 0.232 & 0.236 & 0.111 & - \\
\hline
\end{tabular}

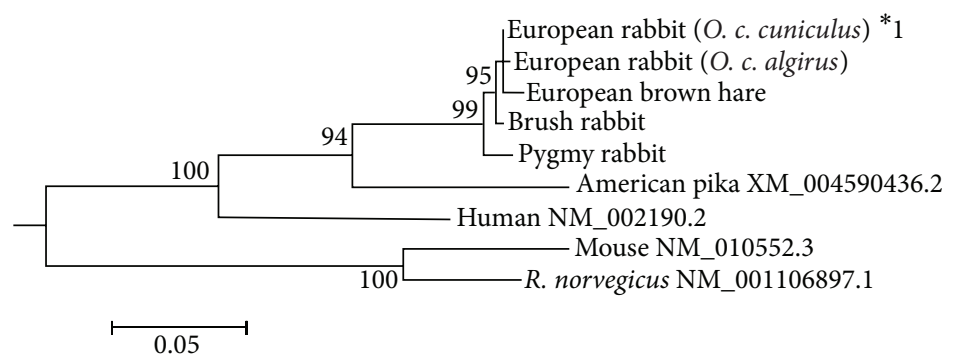

Figure 3: Maximum Likelihood (ML) tree of the IL17A nucleotide sequences. Only bootstrap values $\geq 94 \%$ are shown. In order to facilitate visualization, only one sequence/allele of each species was used.

the European hedgehog also have an extra cysteine located in different sites of the signal peptide (Cys11 and Cys3, resp.). Given that the signal peptide is cleaved in order for the protein to become active, this extra cysteine should not have an impact on the IL17A structure.

$\mathrm{N}$-glycosylation is a crucial factor for the modulation of protein activity; therefore, alteration on these sites may interfere with recognition of targets, including receptors, and consequently affects the biological activity of the proteins and also their ability to diffuse through the organism $[56,57]$. Human IL17A is N-glycosylated at Asn68. Detection of putative $\mathrm{N}$-glycosylation sites indicated that this $\mathrm{N}$-glycosylation site is present in the majority of mammals, including rodents and lagomorphs. Other putative $\mathrm{N}$-glycosylation sites were detected and include Asn56 in lagomorphs, pig, and cattle, Asn51 in American pika and armadillo, and Asn49 in the lesser hedgehog tenrec. The killer whale and the African bush elephant have no putative $\mathrm{N}$-glycosylation sites. The implications of the absence/presence of $\mathrm{N}$-glycosylation sites in IL17A are unknown; however some studies indicate that presence/removal of glycans in some proteins do not alter their folding or function, although a decrease in the protein dynamics is observed $[50,52,57]$.

Comparison of the nucleotide sequences (Table 2) indicated that, in leporids, the European rabbit and the European brown hare IL17A sequences are the least divergent (0.011) while the European rabbit and the pygmy rabbit IL17 sequences are the most divergent (0.026). Between the European rabbit and American pika, the genetic diversity obtained was $0.112-0.115$. For the remaining mammals the highest divergence occurs for the lesser hedgehog tenrec (0.312) and the lowest divergence for the flying lemur (0.145). The comparison of the nucleotide diversity of several interleukins in the European rabbit suggested that it could represent a better animal model for research [34]. For IL17A, similar results were obtained, with the human sequence being more closely related to the European rabbit $(0.169)$ than to mouse or rat IL17A sequences $(0.236)$. This is further supported by a Maximum Likelihood tree inferred for IL17A mammalian sequences (Figure 3).

\section{Conclusions}

In the present study we sequenced and characterized IL17A for four leporids. Overall, the genomic organization, the location of the cysteine residues, and the presence of $\mathrm{N}$ glycosylation sites are highly conserved in leporids. Nevertheless, a single mutation was detected within the interaction site with IL17RA which may induce crucial changes in IL17A structure, function, stability, signaling, and conformation. Further functional and structural studies should be performed to fully understand the impact of this specific mutation. The lowest divergence between the European rabbit and human IL17A sequences reinforces the hypothesis that the European rabbit might be a more suitable animal model for studies in the human innate immunity.

\section{Conflict of Interests}

The authors declare that there is no conflict of interests regarding the publication of this paper. 


\section{Acknowledgments}

The authors would like to thank Jeff Wilcox and Dr. Michael Hamilton from Blue Oak Ranch Reserve, University of California, Berkeley, USA, for providing brush rabbit (Sylvilagus bachmani) tissue samples and Dr. Janet Rachlow, Dr. Lisette Waits, and Dr. Caren Goldberg from Department of Fish and Wildlife Sciences, University of Idaho, USA, for providing pygmy rabbit (Brachylagus idahoensis) tissue samples. This work is funded by National Funds through FCT-Foundation for Science and Technologyunder the Project FCT-ANR/BIA-BIC/0043/2012. FCT also supported the doctoral grants of Fabiana Neves (ref.: SFRH/BD/81916/2011) and the FCT Investigator grant of Joana Abrantes (ref.: IF/01396/2013). "Genomics Applied to Genetic Resources” cofinanced by North Portugal Regional Operational Programme 2007/2013 (ON.2-O Novo Norte), under the National Strategic Reference Framework (NSRF), through the European Regional Development Fund (ERDF), also supported this work.

\section{References}

[1] Z. Yao, S. L. Painter, W. C. Fanslow et al., "Human IL-17: a novel cytokine derived from T cells," Journal of Immunology, vol. 155, no. 12, pp. 5483-5486, 1995.

[2] E. Rouvier, M.-F. Luciani, M.-G. Mattei, F. Denizot, and P. Golstein, "CTLA-8, cloned from an activated T cell, bearing AUrich messenger RNA instability sequences, and homologous to a herpesvirus Saimiri gene," Journal of Immunology, vol. 150, no. 12, pp. 5445-5456, 1993.

[3] S. L. Gaffen, "An overview of IL-17 function and signaling," Cytokine, vol. 43, no. 3, pp. 402-407, 2008.

[4] W. Ouyang, J. K. Kolls, and Y. Zheng, "The biological functions of T helper 17 cell effector cytokines in inflammation," Immunity, vol. 28, no. 4, pp. 454-467, 2008.

[5] S. Gerhardt, W. M. Abbott, D. Hargreaves et al., "Structure of IL-17A in complex with a potent, fully human neutralizing antibody," Journal of Molecular Biology, vol. 394, no. 5, pp. 905921, 2009.

[6] L. K. Ely, S. Fischer, and K. C. Garcia, "Structural basis of receptor sharing by interleukin 17 cytokines," Nature Immunology, vol. 10, no. 12, pp. 1245-1251, 2009.

[7] F. Shen and S. L. Gaffen, "Structure-function relationships in the IL-17 receptor: implications for signal transduction and therapy," Cytokine, vol. 41, no. 2, pp. 92-104, 2008.

[8] N. Y. Hemdan, G. Birkenmeier, G. Wichmann et al., "Interleukin-17-producing T helper cells in autoimmunity," Autoimmunity Reviews, vol. 9, no. 11, pp. 785-792, 2010.

[9] F. L. van de Veerdonk, M. S. Gresnigt, B. J. Kullberg, J. W. M. van der Meer, L. A. B. Joosten, and M. G. Netea, “Th17 responses and host defense against microorganisms: an overview," $B M B$ Reports, vol. 42, no. 12, pp. 776-787, 2009.

[10] E. Bettelli, T. Korn, and V. K. Kuchroo, “Th17: the third member of the effector T cell trilogy," Current Opinion in Immunology, vol. 19, no. 6, pp. 652-657, 2007.

[11] Y. Iwakura, H. Ishigame, S. Saijo, and S. Nakae, "Functional specialization of interleukin-17 family members," Immunity, vol. 34, no. 2, pp. 149-162, 2011.

[12] H. Ishigame, S. Kakuta, T. Nagai et al., "Differential roles of interleukin-17A and -17F in host defense against mucoepithelial bacterial infection and allergic responses," Immunity, vol. 30, no. 1, pp. 108-119, 2009.

[13] W. Huang, L. Na, P. L. Fidel, and P. Schwarzenberger, "Requirement of interleukin-17A for systemic anti-Candida albicans host defense in mice," The Journal of Infectious Diseases, vol. 190, no. 3, pp. 624-631, 2004.

[14] S. A. Khader and R. Gopal, "IL-17 in protective immunity to intracellular pathogens," Virulence, vol. 1, no. 5, pp. 423-427, 2010.

[15] J. A. Skyberg, M. F. Rollins, J. W. Samuel, M. D. Sutherland, J. T. Belisle, and D. W. Pascual, "Interleukin-17 protects against the francisella tularensis live vaccine strain but not against a virulent F. tularensis type A strain," Infection and Immunity, vol. 81, no. 9, pp. 3099-3105, 2013.

[16] C. Paranavitana, E. Zelazowska, L. Dasilva, P. R. Pittman, and M. Nikolich, "Th17 cytokines in recall responses against francisella tularensis in Humans," Journal of Interferon \& Cytokine Research, vol. 30, no. 7, pp. 471-476, 2010.

[17] L. A. Tesmer, S. K. Lundy, S. Sarkar, and D. A. Fox, "Th17 cells in human disease," Immunological Reviews, vol. 223, no. 1, pp. 87-113, 2008.

[18] S. Zhu and Y. Qian, "IL-17/IL-17 receptor system in autoimmune disease: mechanisms and therapeutic potential," Clinical Science, vol. 122, no. 11, pp. 487-511, 2012.

[19] F. Neves, J. Abrantes, J. W. Steinke, and P. J. Esteves, "Maximumlikelihood approaches reveal signatures of positive selection in IL genes in mammals," Innate Immunity, vol. 20, no. 2, pp. 184191, 2014.

[20] K. Kubelkova and A. Macela, "Putting the jigsaw together-a brief insight into the tularemia," Open Life Sciences, vol. 10, no. 1, pp. 195-216, 2015.

[21] M. D. Valentino, Z. J. Maben, L. L. Hensley et al., "Identification of T-cell epitopes in Francisella tularensis using an ordered protein array of serological targets," Immunology, vol. 132, no. 3, pp. 348-360, 2011.

[22] C. L. Carvalho, I. Lopes de Carvalho, L. Zé-Zé, M. S. Núncio, and E. L. Duarte, "Tularaemia: a challenging zoonosis," Comparative Immunology, Microbiology and Infectious Diseases, vol. 37, no. 2, pp. 85-96, 2014.

[23] D. Y. Kim, T. J. Reilly, S. K. Schommer, and S. T. Spagnoli, "Rabbit tularemia and hepatic coccidiosis in wild rabbit," Emerging Infectious Diseases, vol. 16, no. 12, pp. 2016-2017, 2010.

[24] A. Mailles and V. Vaillant, "10 years of surveillance of human tularaemia in France," Eurosurveillance, vol. 19, no. 45, Article ID 20956, 2014.

[25] D. A. Lepitzki, A. Woolf, and M. Cooper, "Serological prevalence of tularemia in cottontail rabbits of southern Illinois," Journal of Wildlife Diseases, vol. 26, no. 2, pp. 279-282, 1990.

[26] G. Wobeser, G. D. Campbell, A. Dallaire, and S. McBurney, "Tularemia, plague, yersiniosis, and Tyzzer's disease in wild rodents and lagomorphs in Canada: a review," Canadian Veterinary Journal, vol. 50, no. 12, pp. 1251-1256, 2009.

[27] J. M. Rijks, M. Kik, M. G. Koene et al., “Tularaemia in a brown hare (Lepus europaeus) in 2013: first case in the Netherlands in 60 years," Eurosurveillance, vol. 18, no. 49, 2013.

[28] G. Hestvik, E. Warns-Petit, L. A. Smith et al., "The status of tularemia in Europe in a one-health context: a review," Epidemiology and Infection, vol. 143, no. 10, pp. 2137-2160, 2015.

[29] C. A. Matthee, B. J. van Vuuren, D. Bell, and T. J. Robinson, "A molecular supermatrix of the rabbits and hares (Leporidae) allows for the identification of five intercontinental exchanges 
during the Miocene," Systematic Biology, vol. 53, no. 3, pp. 433447, 2004.

[30] D. S. Horner, K. Lefkimmiatis, A. Reyes, C. Gissi, C. Saccone, and G. Pesole, "Phylogenetic analyses of complete mitochondrial genome sequences suggest a basal divergence of the enigmatic rodent Anomalurus," BMC Evolutionary Biology, vol. 7, article 16, 2007.

[31] W. J. Murphy, E. Eizirik, W. E. Johnson, Y. P. Zhang, O. A. Ryder, and S. J. O'Brien, "Molecular phylogenetics and the origins of placental mammals," Nature, vol. 409, no. 6820, pp. 614-618, 2001.

[32] P. Schnupf and P. J. Sansonetti, "Quantitative RT-PCR profiling of the rabbit immune response: assessment of acute Shigella flexneri infection," PLoS ONE, vol. 7, no. 6, Article ID e36446, 2012.

[33] B. Fischer, P. Chavatte-Palmer, C. Viebahn, A. Santos, and V. Duranthon, "Rabbit as a reproductive model for human health," Reproduction, vol. 144, no. 1, pp. 1-10, 2012.

[34] F. Neves, J. Abrantes, T. Almeida, A. L. de Matos, P. P. Costa, and P. J. Esteves, "Genetic characterization of interleukins (IL$1 \alpha$, IL-1 $\beta$, IL-2, IL-4, IL-8, IL-10, IL-12A, IL-12B, IL-15 and IL-18) with relevant biological roles in lagomorphs," Innate Immunity, vol. 21, no. 8, pp. 787-801, 2015.

[35] C. Vaure and Y. Liu, "A comparative review of toll-like receptor 4 expression and functionality in different animal species," Frontiers in Immunology, vol. 5, article 316, 2014.

[36] S. Vuillaumier, B. Kaltenboeck, G. Lecointre, P. Lehn, and E. Denamur, "Phylogenetic analysis of cystic fibrosis transmembrane conductance regulator gene in mammalian species argues for the development of a rabbit model for cystic fibrosis," Molecular Biology and Evolution, vol. 14, no. 4, pp. 372-380, 1997.

[37] A. Pinheiro, F. Neves, A. Lemos de Matos et al., "An overview of the lagomorph immune system and its genetic diversity," Immunogenetics, In press.

[38] P. Librado and J. Rozas, "DnaSP v5: a software for comprehensive analysis of DNA polymorphism data," Bioinformatics, vol. 25, no. 11, pp. 1451-1452, 2009.

[39] R. C. Edgar, "MUSCLE: multiple sequence alignment with high accuracy and high throughput," Nucleic Acids Research, vol. 32, no. 5, pp. 1792-1797, 2004.

[40] R. Gupta, E. Jung, and S. Brunak, Prediction of N-Glycosylation Sites in Human Proteins, 2004.

[41] K. Tamura, G. Stecher, D. Peterson, A. Filipski, and S. Kumar, "MEGA6: molecular evolutionary genetics analysis version 6.0," Molecular Biology and Evolution, vol. 30, no. 12, pp. 2725-2729, 2013.

[42] D. W. A. Buchan, F. Minneci, T. C. O. Nugent, K. Bryson, and D. T. Jones, "Scalable web services for the PSIPRED Protein Analysis Workbench," Nucleic Acids Research, vol. 41, pp. W349-W357, 2013.

[43] D. T. Jones, "Protein secondary structure prediction based on position-specific scoring matrices," Journal of Molecular Biology, vol. 292, no. 2, pp. 195-202, 1999.

[44] F. Ferrè and P. Clote, "DiANNA 1.1: an extension of the DiANNA web server for ternary cysteine classification," Nucleic Acids Research, vol. 34, pp. W182-W185, 2006.

[45] S. Liu, X. Song, B. A. Chrunyk et al., "Crystal structures of interleukin 17A and its complex with IL-17 receptor A," Nature Communications, vol. 4, article 188, 2013.

[46] R. Sabat, E. Witte, K. Witte, and K. Wolk, "IL-22 and IL-17: an overview," in IL-17, IL-22 and Their Producing Cells: Role in
Inflammation and Autoimmunity, V. Quesniaux, B. Ryffel, and F. D. Padova, Eds., Springer, 2013.

[47] C. Ferrer-Costa, M. Orozco, and X. de la Cruz, "Characterization of disease-associated single amino acid polymorphisms in terms of sequence and structure properties," Journal of Molecular Biology, vol. 315, no. 4, pp. 771-786, 2002.

[48] S. Fang, B. Chen, F. P. L. Tay, B. S. Ng, and D. X. Liu, "An arginine-to-proline mutation in a domain with undefined functions within the helicase protein (Nsp13) is lethal to the coronavirus infectious bronchitis virus in cultured cells," Virology, vol. 358, no. 1, pp. 136-147, 2007.

[49] M. W. Yap, S. Nisole, and J. P. Stoye, "A single amino acid change in the SPRY domain of human Trim $5 \alpha$ leads to HIV-1 restriction," Current Biology, vol. 15, no. 1, pp. 73-78, 2005.

[50] A. Helenius and M. Aebi, "Roles of N-linked glycans in the endoplasmic reticulum," Annual Review of Biochemistry, vol. 73, pp. 1019-1049, 2004.

[51] P. M. Rudd, T. Elliott, P. Cresswell, I. A. Wilson, and R. A. Dwek, "Glycosylation and the immune system," Science, vol. 291, no. 5512, pp. 2370-2376, 2001.

[52] H. S. Lee, Y. Qi, and W. Im, "Effects of N-glycosylation on protein conformation and dynamics: Protein Data Bank analysis and molecular dynamics simulation study," Scientific Reports, vol. 5, article 8926, 2015.

[53] D. Fass, "Disulfide bonding in protein biophysics," Annual Review of Biophysics, vol. 41, no. 1, pp. 63-79, 2012.

[54] S. G. Hymowitz, E. H. Filvaroff, J. Yin et al., "IL-17s adopt a cystine knot fold: structure and activity of a novel cytokine, IL$17 F$, and implications for receptor binding," The EMBO Journal, vol. 20, no. 19, pp. 5332-5341, 2001.

[55] J. F. Wright, F. Bennett, B. Li et al., “The human IL-17F/IL-17A heterodimeric cytokine signals through the IL-17RA/IL-17RC receptor complex," The Journal of Immunology, vol. 181, no. 4, pp. 2799-2805, 2008.

[56] A.-L. Chamorey, N. Magné, X. Pivot, and G. Milano, "Impact of glycosylation on the effect of cytokines. A special focus on oncology," European Cytokine Network, vol. 13, no. 2, pp. 154$160,2002$.

[57] D. Shental-Bechor and Y. Levy, "Effect of glycosylation on protein folding: a close look at thermodynamic stabilization," Proceedings of the National Academy of Sciences of the United States of America, vol. 105, no. 24, pp. 8256-8261, 2008. 


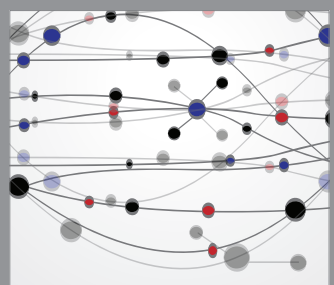

The Scientific World Journal
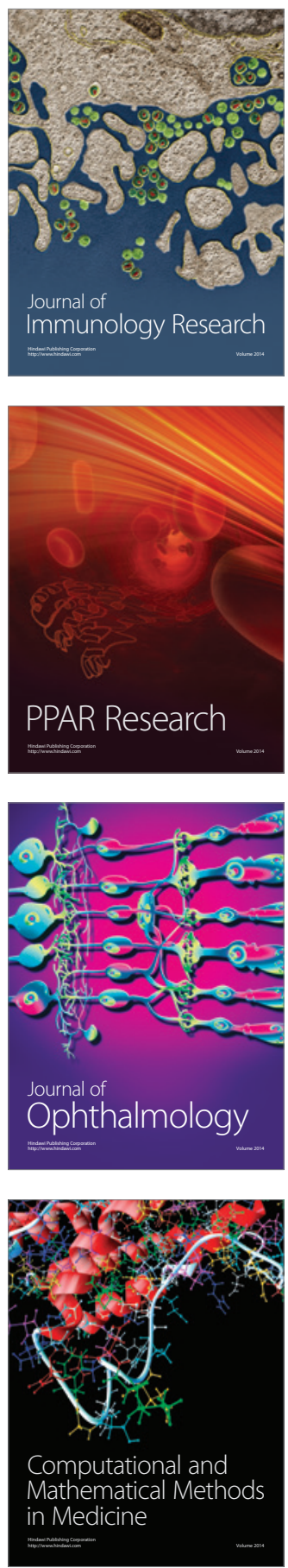

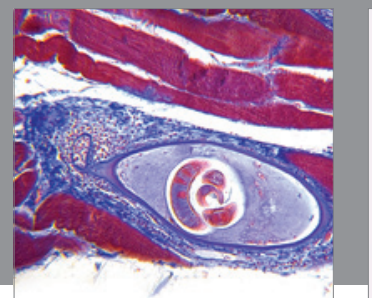

Gastroenterology

Research and Practice
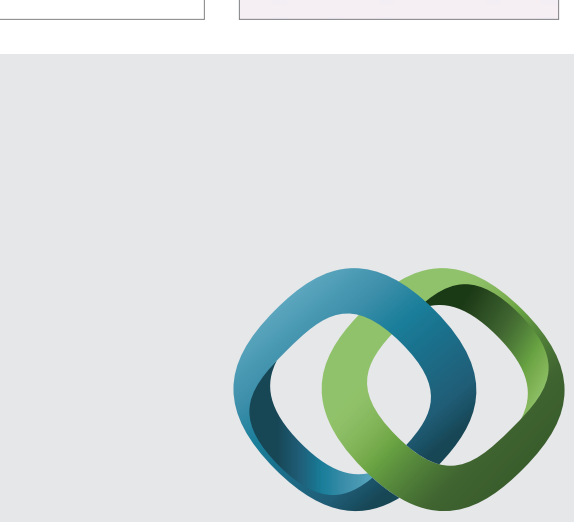

\section{Hindawi}

Submit your manuscripts at

http://www.hindawi.com
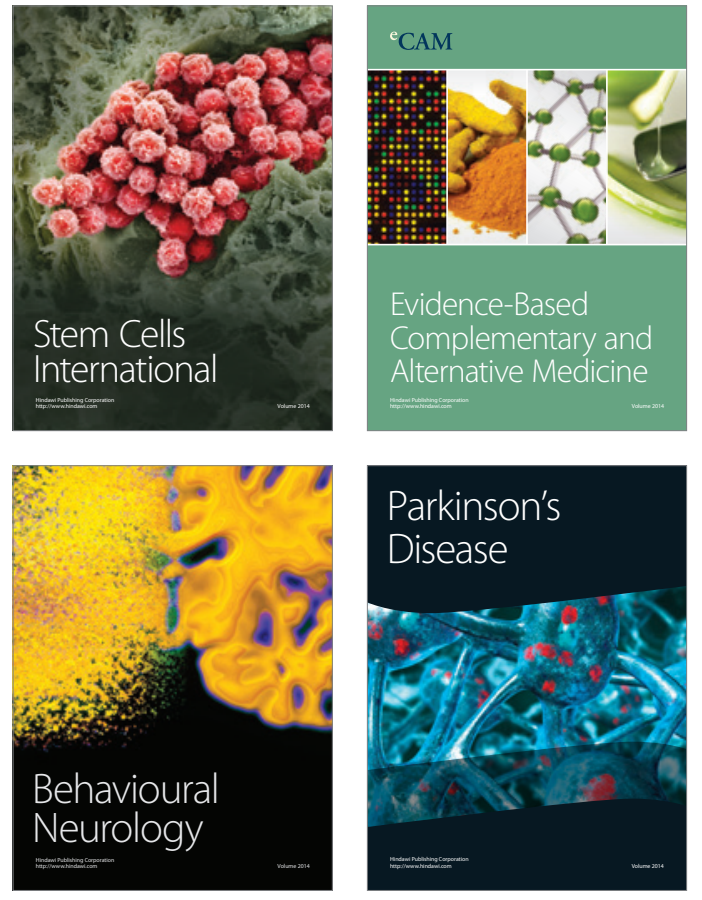
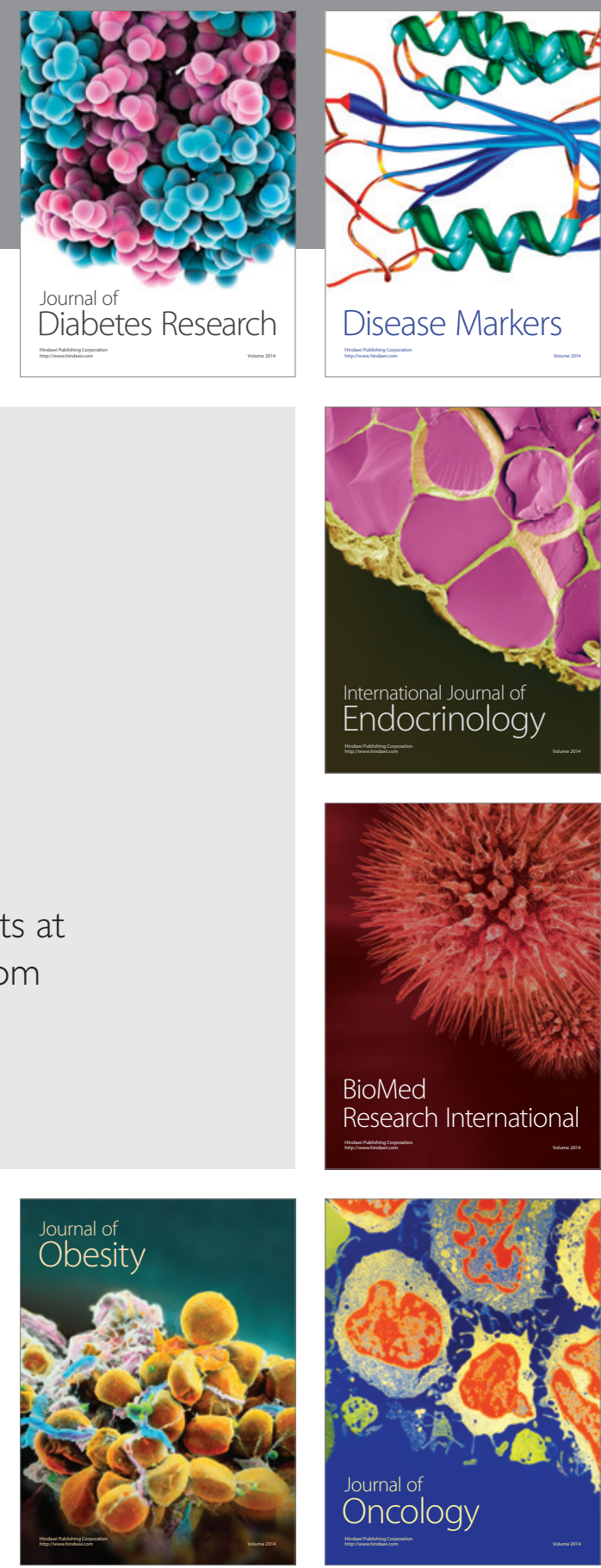

Disease Markers
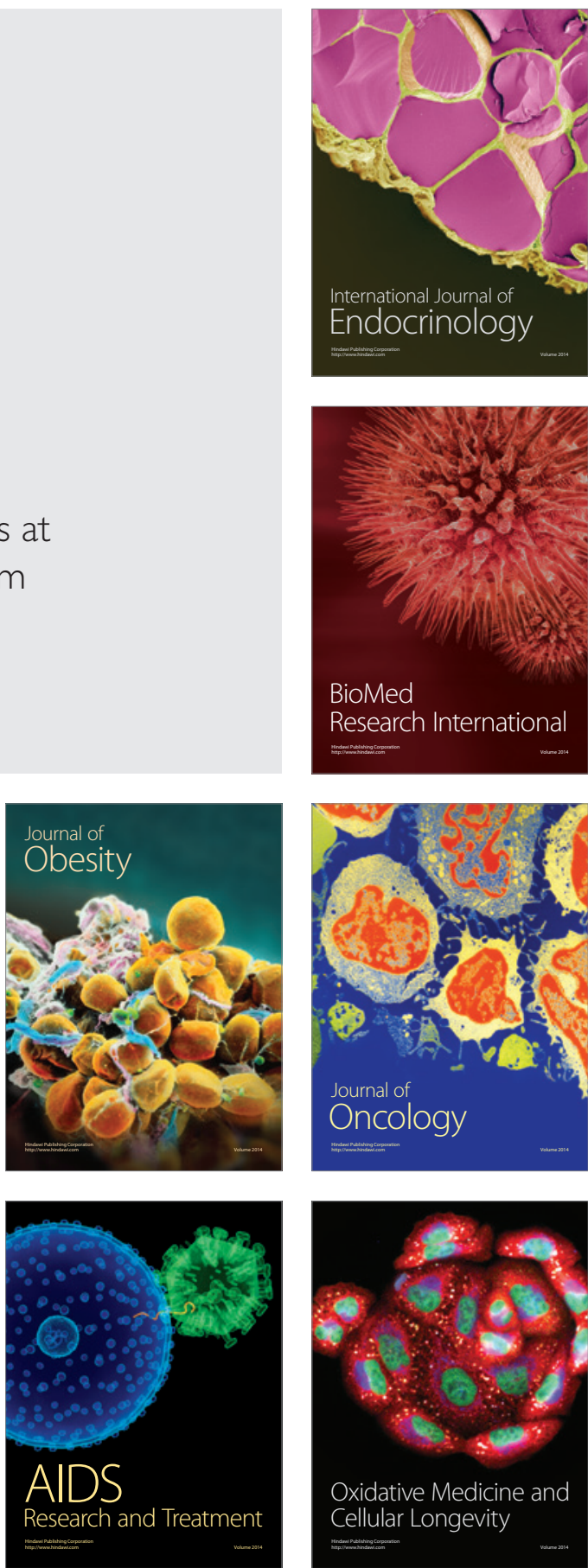